\title{
UPAYA MENJAGA KEBERSIHAN SEKOLAH PADA SAAT COVID 19 DENGAN MEMBERDAYAKAN TENAGA GURU DI SDN PEKAYON 03 KEC. PASAR REBO JAKARTA TIMUR
}

\author{
SRI MUJIATI* \\ SDN PEKAYON 03, Jakarta Timur, DKI Jakarta, Indonesia \\ *Email:srimuizat153@gmail.com
}

\begin{abstract}
Informasi Artikel
Abstrak

Kata kunci:

Sekolah Dasar, Covid19, Lingkungan Sekolah.

Diterima: $12-10-2020$

Disetujui: 20-10-2020

Dipubikasikan: 26-10-2020

Upaya menjaga kebersihan sekolah saat covid-19 di SDN Pekayon 03 Kec. Pasar Rebo Jakarta Timur. Keberadaan taman sekolah merupakan hal terpenting yang ada di sekolah agar terlaksananya pendidikan yang mengutamakan kesehatan atau kebiasaan hidup sehat di sekolah yang diterapkan di lingkungan sekitar terutama pada saat situasi covid 19. Oleh sebab itu tujuan dari penelitian ini adalah untuk mengetahui seberapa baik Pelaksanaan Kebersihan oleh guru-guru piket di Sekolah Dasar Negeri Pekayon 03 Kec. Pasar Rebo tahun 2020. Penelitian ini merupakan penelitian kualitatif, dengan menggunakan metode survey langsung. Analisis data yang terkumpul menggunakan deskriptif. Populasi dalam penelitian ini adalah semua Guru di SDN Pekayon $03 \mathrm{Kec}$. Pasar Rebo Jakarta Timur berjumlah 22 Orang Guru. Hasil penelitian tentang upaya menjaga kebersihan sekolah pada saat covid 19 dengan memberdayakan tenaga guru di SDN Pekayon 03 Kec. Pasar Rebo Jakarta Timur
\end{abstract}

\section{PENDAHULUAN}

Sekolah merupakan sebuah lembaga formal, tempat anak didik memperoleh pendidikan dan pelajaran yang diberikan oleh guru, atau dapat juga diartikan Sekolah adalah suatu wadah untuk melaksanakan proses belajar mengajar. Namun sejak wabah Covid-19 berlangsung, seluruh aktivitas umumnya dilakukan di rumah melalui sistem dalam jaringan (daring). Tak terkecuali pendidikan yang ikut terkena dampak wabah Covid-19. Hal ini tidak menyurutkan semangat belajar-mengajar di SDN Pekayon 03 Kec. Pasar Rebo Jakarta Timur.

Dengan menggunakan sistem daring, siswa tetap belajar dan mengasah kemampuan akademik maupun non akademik. Didukung kerja kreatif para guru, siswa tetap memperoleh pendidikan yang tepat meski dalam 
keterbatasan ruang. Kreativitas guru dalam menyajikan kegiatan belajar terus mendukung perkembangan dan menstimulus kecerdasan siswa. Seperti memberikan tugas sesuai dengan tema belajar yang sedianya sudah dirancang.

Kali ini siswa belajar mengenali lingkungan sekitar, yaitu air dan udara. Jika biasanya siswa akan langsung melaksanakan praktik, kali ini sedikit berbeda. Dengan media video, guru akan membuat beberapa bentuk yang menggambarkan air dan udara. Kemudian siswa menyontoh dalam membuat karya, seperti pada video yang dibuat guru.

Untuk menjelaskan kegunaan udara, siswa dikenalkan benda-benda yang berkaitan dengan penggunaan udara pada benda. Seperti untuk ban kendaraan, balon, serta benda lain yang berhubungan dengan udara. Dalam menerangkan manfaat air, siswa diajarkan dengan praktik langsung. Salah satunya mencuci piring kotor, mandi, minum dan berbagai kegiatan positif lain yang menggunakan air. Tidak lupa dalam kegiatan ini orang tua juga dilibatkan untuk mengawasi siswa saat praktik.

Selain kegiatan di atas, tidak lupa guru juga menyampaikan pentingnya menjaga kebersihan selama wabah Covid-19. Disertai pula dengan memberikan pengetahuan tentang keagamaan. Dua hal ini dilakukan secara bersamaan, yaitu dengan mengajarkan praktik berwudhu. "Seperti yang diajarkan Rasulullah, menjaga kebersihan itu penting. Salah satu yang diajarkan oleh Rasulullah adalah dengan melakukan wudhu sebelum melaksanakan shalat lima waktu," yang disampaikan oleh Sri Mujiati sebagai Kepala Sekolah. Melalui pembelajaran yang kreatif dan terjangkau dengan keadaan di rumah, siswa tetap dapat belajar dengan baik. Meskipun terdapat berbagai kendala, dengan ketelatenan dan kreativitas guru, kendala tidak akan mengurangi inti dari pendidikan tersebut.

Namun guru-guru diberi tugas piket oleh Kepala Sekolah untuk menetap di Sekolah, selain mengerjakan administrasi sekolah Guru juga melaksanakan piket kebersihan terutama menjaga kebersihan Taman Sekolah di SDN Pekayon 03. Di Sekolah juga ada tempat untuk meningkatkan kesehatan warga sekolah, karena kesehatan dapat diperoleh individu dengan memelihara kesehatan setiap hari. Individu yang melakukan kebiasaan kegiatan aktivitas kesehatan yang dengan baik, maka akan baik pula kesehatan individu. Pendidikan kesehatan dan pelayanan kesehatan yang optimal, tentunya dapat membantu terbentuknya konsentrasi sehingga individu dapat belajar dengan baik. Sesuai dengan penelitian yang sudah dilakukan oleh Reindrawati bahwa Kegiatan sosialisasi menjaga kebersihan ini penting untuk meningkatkan pengetahuan dan kemampuan anak taman kanak-kanak. Pengetahuan tersebut sebagai awal bekal untuk meningkatkan awareness siswa usia dini untuk menjaga kebersihan dan Kesehatan (Reindrawati, 2020). Selanjutnya, dengan dukungan prang tua, guru, dan lingkungan maka diharapkan pembiasaan menjaga kebersihan menjadi terbentuk.Pendidikan kesehatan dan pelayanan kesehatan perlu dilakukan di sekolah agar dalam proses pertumbuhan dan perkembangan anak tidak terjadi hal yang tidak diinginkan. Peran guru yang semakin tinggi dalam pendidikan 
kesehatan dan pelayanan kesehatan di sekolah semakin besar pula tingkat pertumbuhan dan perkembangan peserta didik. Salah satu usaha yang dilakukan untuk meningkatkan kemampuan hidup sehat peserta didik adalah melalui Piket Kebersihan.

Kebersihan di lingkungan sekolah bukan hanya tanggung jawab siswa, akan tetapi juga menjadi tanggungjawab guru dan semua yang ada di sekolah. Namun pada kenyataannya, masih banyak sekolah yang lingkungannya belum terjaga. Yang menjadi penyebab tidak terjaganya lingkungan sekolah, yaitu karena kurangnya kesadaran dalam menjaga kebersihan lingkungan sekolah (Widya, 2020). Dalam lingkungan sekolah guru merupakan sosok yang paling berpengaruh terhadap siswa, karena apapun yang guru lakukan siswa akan mengikutinya

Guru merupakan motivator terdekat dengan para siswa. Siswa belajar dari apa yang mereka lihat. Maka alangkah baiknya jika guru dapat mengajak dan memberi contoh kepada siswanya tentang menjaga kebersihan agar tercipta suasana lingkungan yang bersih dan nyaman. Cara menciptakan lingkungan sekolah yang sehat diantaranya :1. Hal pertama yang dapat dilakukan adalah mencanangkan program sekolah hijau (green school). Program penghijauan sekolah, selain membuat sekolah menjadi rindang, juga bisa memberi kenyamanan saat kegiatan belajar mengajar. 2. Melaksanakan tata tertib sekolah dan tetap menjaga kebersihan dan keseimbangan lingkungan sekolah. 3. Menanamkan sikap peduli lingkungan terhadap siswa dengan mencanangkan berbagai program yang bisa menyadarkan siswa betapa pentingnya menjaga kebersihan dan kesehatan lingkungan seko-lah.4 .Melakukan pengawasan yang ketat dan penegakkan peraturan sekolah yang tegas agar para warga sekolah mau dan secara sadar bersedia untuk melaksanakan ketertiban dan peraturan sekolah.5.Mencanagkan kegiatan cinta lingkungan atau kegiatan kebersihan sekolah.

Pendidikan menjadi garda depan dalam upaya pembentukan karakter manusia Indonesia yang sesungguhnya dan sekolah merupakan sektor utama yang secara optimal memanfaatkan dan memperdayakan semua lingkungan belajar yang ada untuk menginisiasi, memperbaiki, menguatkan, dan menyempurnakan secara terus menerus melalui proses pendidikan karakter di sekolah (Al-anwari, n.d.). Berdasarkan hasil observasi dan mengingat pentingnya diketahui keadaan yang sebenarnya, Upaya menjaga kebersihan sekolah pada saat situasi covid 19 di SDN Pekayon 03 Kec. Pasar Rebo Jakarta Timur.

\section{METODE}

Penelitian yang dilakukan menggunakan pendekatan kualitatif dengan metode deskriptif. Penelitian ini bertujuan untuk mendeskripsikan Upaya menjaga kebersihan sekolah pada saat situasi covid 19 di SDN Pekayon 03 Kec. Pasar Rebo Jakarta Timur. Dalam penelitian ini dilakukan penggalian data dengan mengamati dan mendengarkan secara seksama setiap penuturan informan yang berkaitan dengan pembentukan perilaku peduli lingkungan pada siswa melalui sekolah SDN Pekayon 03 Kec. Pasar Rebo Jakarta Timur. 
Waktu penelitian dilakukan dari awal sampai akhir (hasil penelitian) sekitar 3 bulan yaitu dari bulan Maret 2020 sampai dengan July 2020. Creswell (2009:286) mengatakan bahwa kedalaman yang dimunculkan dalam penelitian kualitatif ini lebih berhubungan dengan kekayaan informasi dan kecocokan konteks apa yang ingin diketahui oleh peneliti daripada tergantung pada jumlah sampel. Pada penelitian ini yang dijadikan informan penelitian adalah orang yang mengetahui tentang pembentukan perilaku peduli lingkungan siswa melalui sekolah SDN Pekayon 03 Kec. Pasar Rebo Jakarta Timur. yaitu guru dan penjaga sekolah. Teknik yang digunakan untuk mengumpulkan data dalam penelitian ini adalah teknik pengamatan (Observasi) merupakan pengamatan langsung yang dilakukan dengan turun kelapangan untuk mengamati perilaku dan aktivitas individu-individu di lokasi penelitian (Creswell, 2004:267). Pengamatan dilakukan untuk mencari gambaran awal mengenai lokasi penelitian Kajian Moral dan Kewarganegaraan dan menentukan informan penelitian dengan melakukan pengamatan. Observasi dalam penelitian ini dilakukan dengan melakukan pengamatan ke seluruh area sekolah terhadap aktivitas guru di masa pendemi covid 19 berkaitan dengan upaya menjaga kebersihan sekolah di SDN Pekayon 03 Kec. Pasar Rebo Jakarta Timur

Wawancara adalah teknik pengumpulan data apabila peneliti ingin melakukan studi pendahuluan untuk menemukan permasalahan yang harus diteliti tetapi juga apabila peneliti ingin mengetahui hal-hal dari responden yang lebih mendalam. Wawancara dilakukan untuk mengetahui upaya dari pihak sekolah SDN Pekayon 03 Kec. Pasar Rebo Jakarta Timur. Sejauh mana pengetahuan dan upaya mereka sebagai informan dalam upaya menjaga kebersihan sekolah di SDN Pekayon 03 Kec. Pasar Rebo Jakarta Timur.

Dokumentasi dilakukan untuk mengumpulkan data yang bersumber dari arsip dan dokumen milik sekolah yang ada hubungannya dengan penelitian ini. Dalam penelitian ini, teknik dokumentasi yang dimaksud adalah dapat berupa foto seperti tempat sampah, foto slogan dan poster maupun foto kegiatan guru seperti pembersihan kelas, penanaman pohon, merawat taman, dan pemilahan sampah plastic.

Dalam penelitian ini menggunakan teknik analisis model Miles and Huberman. Menurut (Miles and Huberman dalam Sugiyono, 2005: 91) "mengemukakan bahwa aktivitas analisis data kualitatif dilakukan secara interaktif dan berlangsung secara terus menerus sampai tuntas, sehingga datanya sudah jenuh." Aktivitas analisis data yaitu yang pertama data Reduction (Reduksi Data) adalah Mereduksi dan berarti merangkum, memilih hal-hal yang pokok, memfokuskan pada hal-hal yang penting. Data yang direduksi akan memberikan gambaran yang lebih jelas, dan mempermudah penulis untuk melakukan pengumpulan data selanjutnya, dan mencarinya bila diperlukan. Data penelitian ini, data diperoleh melalui wawancara kemudian data tersebut dirangkum, dan diseleksi sehingga akan memberikan gambaran yang jelas kepada penulis. Langkah kedua yaitu data display atau menyajikan data. Penyajian data dilakukan dengan mengelompokkan data sesuai dengan sub babnya masing-masing. Data yang telah didapatkan dari hasil wawancara, dari sumber tulisan maupun dari sumber pustaka dikelompokkan. 
Langkah yang terakhir dilakukan dalam analisis data kualitatif adalah penarikan kesimpulan dan verifikasi. Simpulan awal yang dikemukakan masih bersifat sementara, dan akan berubah apabila tidak ditemukan bukti yang kuat yang mendukung pada tahap pengumpulan data berikutnya. Simpulan dalam penulisan kualitatif merupakan temuan baru yang sebelumnya belum pernah ada. Temuan dapat berupa deskripsi atau gambaran suatu obyek yang sebelumnya kurang jelas sehingga menjadi jelas setelah diteliti. Untuk memeriksa keabsahan data dalam penelitian ini, peneliti menggunakan teknik triangulasi. Menurut Sugiyono (2010:330) triangulasi teknik berarti peneliti menggunakan teknik pengumpulan data yang berbedabeda untuk mendapatkan data dari sumber data yang sama. Triangulasi teknik untuk menguji kredibilatas data dilakukan dengan cara mengecek data kepada sumber yang sama dengan teknik yang berbeda. Misalnya data diperoleh dengan wawancara, lalu dicek dengan observasi, dokumentasi, atau kuesioner. Bila dengan teknik pengujian kredibilitas data tersebut, menghasilkan data yang berbeda-beda, maka peneliti melakukan diskusi lebih lanjut kepada sumber data yang bersangkutan atau yang lain, untuk memastikan data mana yang dianggap benar. Atau mungkin semuanya benar, karena sudut pandangnya berbeda-beda.

\section{HASIL DAN PEMBAHASAN}

Bisa karena biasa. Pepatah ini bisa menjadi gambaran saat melakukan Upaya menjaga kebersihan sekolah pada saat situasi covid 19 di SDN Pekayon 03 Kec. Pasar Rebo Jakarta Timur

Membuang sampah, menjaga kelestarian taman, kelas maupun sekolah atau mencuci tangan menjadi sejumlah sikap yang bisa dilakukan spontan bila telah dibiasakan untuk hidup bersih. Pembiasaan ini perlu diterapkan di mana saja, terutama di sekolah. Di sekolah, guru perlu memiliki strategi agar kebiasaan hidup bersih dapat dilakukan dengan hidup bersih tak hanya berdampak pada kebersihan lingkungan sekolah, namun juga melatih kepekaan anak terhadap lingkungan sekitar dan membantu anak bertanggung jawab terhadap dirinya sendiri.

Berikut cara untuk melatih agar menjaga kebersihan sekolah pada saat situasi covid 19 di SDN Pekayon 03 Kec. Pasar Rebo Jakarta Timur.

\section{Sediakan Tempat Sampah}

Menjaga kebersihan lingkungan bisa dimulai dari aktivitas sederhana yakni membuang sampah pada tempatnya. Guru dan pihak sekolah bisa membuat rambu-rambu untuk tidak membuang sampah sembarangan. 


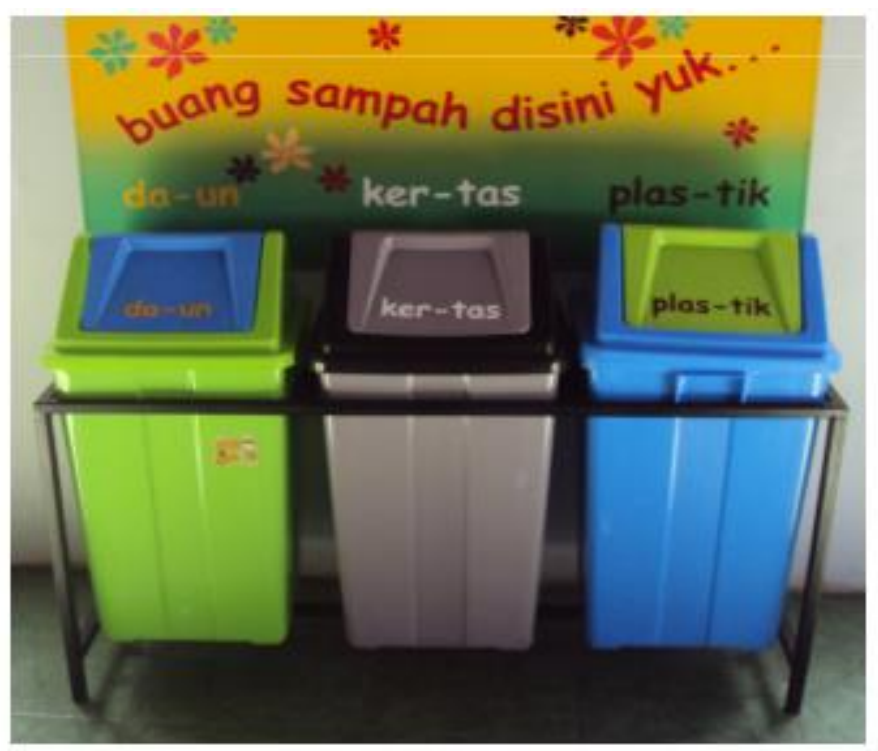

Gambar 1. Tempat Sampah yang tersedia di SD

\section{Budaya saling mengingatkan}

Guru perlu mengajak sesame guru untuk mengingatkan warga sekolah yang lupa membuang sampah pada tempatnya. Beri pemahaman bahwa kebersihan sekolah dan lingkungan adalah tanggung jawab bersama, sehingga mereka harus saling mewujudkan dan menjaganya.

\section{Contoh dari pimpinan sekolah}

Pimpinan sekolah perlu memberi contoh nyata pada dewan guru, sebab mudah meniru ketimbang melaksanakan nasihat. Tanpa adanya kerja sama banyak pihak, kebersihan lingkungan akan sulit terwujud. Pimpinan Sekolah dan guru bisa memberi contoh untuk peduli pada kebersihan lingkungan sekolah dengan cara memungut sampah yang tercecer.

\section{Rutin bersihkan kelas}

Buat jadwal rutin untuk bersama-sama membersihkan ruangan kelas dengan suasana yang menyenangkan agar sesi bersih-bersih tidak seperti beban.

\section{Peduli toilet}

Toilet biasanya menjadi ukuran bersih atau tidaknya suatu lingkungan sekolah. Kalau toiletnya bersih, biasanya bagian lain dari sekolah juga akan bersih, asri dan tertata dengan baik. Sebaliknya, jika kondisi toiletnya kotor dan bau, biasanya bagian lainnya juga demikian. Jadi, ingatkan dewan guru Bersama warga sekolah untuk menjaga kebersihan dengan menyiram toilet sampai bersih setelah memakainya. Ajak warga sekolah untuk selalu mencuci tangan usai ke toilet atau membuang sampah demi kesehatan diri. 


\section{Keasrian Lingkungan}

Bersih saja tak cukup, agar lingkungan sekolah nyaman, keasrian sekolah juga perlu mendapat perhatian. Untuk membuat lingkungan sekolah lebih asri, guru dan pihak sekolah bisa menetapkan hari tertentu untuk mengajak sesame dewan guru untuk menanam bunga, sayur dan pohon. Selain membuat lingkungan sekolah indah dan sejuk, dewan guru juga akan turut menjaganya, karena tanaman tersebut mereka yang menanam.

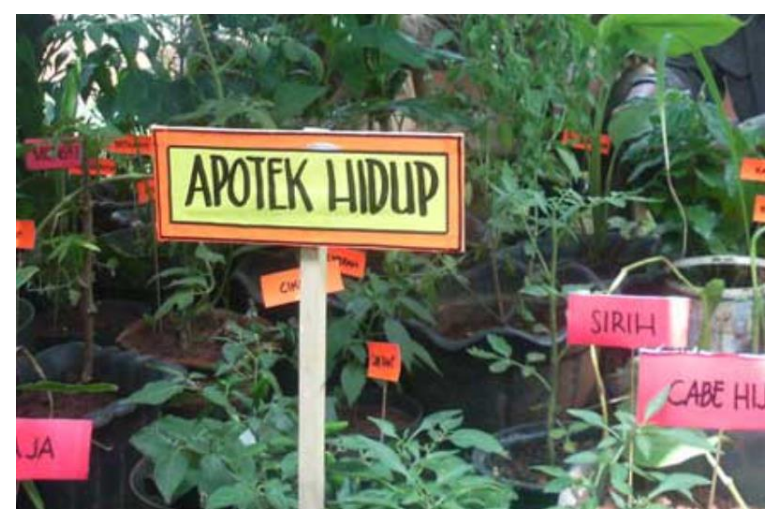

Gambar 2. Tamanan Apotek Hidup di Lingkungan Sekolah

\section{Sudut kreatif}

Salah satu masalah yang kerap dihadapi guru maupun orangtua saat menjaga kebersihan lingkungan ialah dinding yang kotor akibat tempelan pengumuman dari sekolah disaat sekolah diliburkan karena pendemi. Perlu dipahami bahwa anak membutuhkan media yang luas untuk menuangkan kreativitas, dan bentuk vertikal seperti dinding adalah media yang paling mudah digambar. Menyediakan satu dinding khusus untuk menggambar bisa menjadi solusi. Selain, lebih tersusun, bersih dan terstruktur, dinding tersebut akan memiliki nilai seni tersendiri.

Tujuan dari Program Green and Clean diantaranya yaitu:1. Membantu dalam upaya pelestarian lingkungan sekolah dengan melakukan kegiatan penghijauan, pemeliharaan, dan perawatan lingkungan sekolah yang tertata dan bersih. Menarik perhatian siswa dalam kepedulian lingkungan sekolah.3. Meningkatkan kepekaan dan motivasi terhadap siswa akan pentingnya berpartisipasi dalam penghijauan dan kebersihan lingkungan sekolah. 4 Mengembangkan semangat kerelawanandi kalangan siswa yang terlibat langsung dalam kegiatan ini (Liyun et al., 2017).

\section{Hambatan}

Hambatan guru dalam upaya menjaga kebersihan sekolah pada saat covid 19 tentunya mengalami kendala atau hambatan. Terdapat hambatan dari luar sekolah dalam upaya menjaga kebersihan sekolah pada saat covid 19 yakni pengaruh lingkungan sekitar yang kurang kondusif dikarenakan sekolah dijadikan tempat bermain warga sekitar yang tingkat kepedulian kebersihan lingkungannya masih rendah. Sehingga 
menyebabkan pihak sekolah terutama guru dan penjaga sekolah berupaya lebih keras lagi dalam menjaga kebersihan sekolah pada saat covid 19.

\section{Solusi}

Solusi untuk mengatasi hambatan dalam upaya menjaga kebersihan sekolah pada saat covid 19 Setiap hambatan tentunya ada solusi atau pemecahan yang telah dilakukan. Solusi yang dimusyawarahkan adalah mengadakan piket sekolah selama WFO (Work From Office) oleh guru-guru dan pegawai sekolah lainnya. Dengan piket sekolah itu diharapkan dapat memantau kebersihan sekolah disaat pendemi.

\section{KESIMPULAN}

Penerapkan pembelajaran jarak jauh sudah lebih dari 1 semester ini, namun upaya menjaga kebersihan dan kesehatan lingkungan sekolah tetap dilaksanakan. Terlebih lagi di masa-masa pandemi Covid-19 seperti saat ini yang hanya bisa dilakukan oleh dewan guru dan penjaga sekolah. Upaya yang dapat dilakukan adalah tersedianya tempat sampah, budaya saling mengingatkan, contoh dari pimpinan sekolah, rutin bersihkan sekolah, program peduli toilet, keasrian sekolah, penyediaan sudut kreatif di sekolah. Lingkungan sekolah yang bersih menjadikan hidup lebih sehat, udara terasa sejuk, belajar menjadi nyaman, serta kelas menjadi bersih dan terhindar dari penyakit. Untuk kebersihan lingkungan sekolah, pengetahuan tentang lingkungan perlu diberikan kepada siswa sejak dini agar dapat mem-berikan pemahaman yang lebih dalam te-tang pentingnya lingkungan bagi manusia sehingga dapat menghasilkan warga Negara yang mempunyai perilaku yang ber-tanggung jawab terhadap lingkungannya dan menumbuhkan rasa kesadaran lingkungan.

\section{UCAPAN TERIMAKASIH}

Terimakasih kepada Tenaga Pendidik dan Kependidikan di SDN Pekayon 03 Kec. Pasar Rebo Jakarta Timur serta Dinas Pendidikan Pemerintah Provinsi DKI Jakarta yang telah berpartisipasi dan memotivasi materil dan inmateril dalam penelitian ini.

\section{DAFTAR PUSTAKA}

Al-anwari, A. M. (n.d.). Strategi pembentukan karakter peduli lingkungan di sekolah adiwiyata mandiri. $\operatorname{XIX}(02)$

Aryanti, W. S. (2020). MENJAGA KEBERSIHAN SEKOLAH DAN KARAKTER PEDULI LINGKUNGAN BAGI MURID MI/SD DI INDONESIA. JURNAL ILMLAH EDUKATIF, 6(1), 76-85.

Creswell, John W. 2004. Research Design (Pendekatan Kualitatif, uantitatif dan mixed). Yogyakarta: Pustaka Pelajar.

Creswell, John W. 2009. Research Design (Pendekatan Kualitatif, uantitatif dan mixed). Yogyakarta: Pustaka Pelajar. 
Liyun, N., Khasanah, W. N., \& Tsuraya, N. A. (2017). MENANAMKAN KARAKTER CINTA LINGKUNGAN PADA ANAK MELALUI PROGRAM “ GREEN AND CLEAN" Universitas Negeri Semarang. 201.

Makhsyari, M. A., Handayani, D. E., \& Prasetyo, S. A. (2018). Penerapan Perilaku Hidup Bersih dan Sehat dalam Menanamkan Nilai Karakter Siswa. MODELING: Jurnal Program Studi PGMI, 5(1).

Rahmawati, I., \& Suwanda, I. (2015). Upaya Pembentukan Perilaku Peduli Lingkungan Siswa Melalui Sekolah Adiwiyata Di SMP Negeri 28 Surabaya. Kajian moral dan kewarganegaraan, 1(3), 71-88.

Reindrawati, D. Y. (2020). Pembiasaan Menjaga Kebersihan Sejak Usia Dini (Pengabdian Pada Murid TK Bintang Kecil Surabaya). Jurnal Anadara Pengabdian Kepada Masyarakat, 2(1).

Sari, P. N., \&Nofriya. (2018). Pembentukan Perilaku Peduli Lingkungan Hidup Menuju Sekolah Adiwiyata pada SDN 05 Kampung Pisang Kecamatan IV Koto. Warta Pengabdian Andalas, 25(2).

Sugiyono. 2010. Metode Penelitian Kuantitatif, Kualitatif dan R \& D. Bandung: Alfabeta. 